ORIGINAL ARTICLE

\title{
Cost of ambulatory care of diabetes mellitus: a study from north India
}

\author{
S Grover, A Avasthi, A Bhansali, S Chakrabarti, P Kulhara
}

Postgrad Med J 2005;81:391-395. doi: 10.1136/pgmj.2004.024299

See end of article for authors' affiliations .....................

Correspondence to: Dr A Bhansali, Department of Endocrinology, Postgraduate Institute of Medical Education and Research (PGIMER) Chandigarh 160012, India; pgimer@chd.nic.in

Submitted 19 May 2004 Accepted 21 August 2004

\begin{abstract}
Background: Diabetes mellitus is a chronic and potentially disabling disease that represents an important public health and clinical concern because of the economic burden it imposes on the person, family, and society. Despite this, data regarding cost of care of diabetes mellitus from developing countries are scarce. This study aimed to assess the cost of care of Indian patients with diabetes mellitus.

Methods: Cost of illness in 50 outpatients with diabetes mellitus (diagnosed according to WHO criteria, Expert Committee, 1997) was assessed over a six month period using a specially designed questionnaire, together with structured assessments of disability.

Results: Total annual cost of care was 14508 rupees (263.78 euros). The largest proportion of the total cost was made up of direct costs $(68 \%)$, followed by indirect costs $(28.76 \%)$ and provider's costs $(2.8 \%)$. Drug costs were high. Total treatment cost was significantly higher in those who were more educated, those who visited the hospital more often, and those receiving a greater number of drugs.

Conclusion: From this study it can be concluded that diabetes mellitus is an expensive illness to treat even in developing countries. The main brunt of financial burden is borne by the family. Any efforts at cost reduction should, therefore, have the family as its focus, and relieving the family of this financial burden needs to be prioritised.
\end{abstract}

D iabetes mellitus is a chronic and potentially disabling disease that represents an important public health and clinical concern. People with diabetes mellitus are at increased risk of developing long term complications related to cardiovascular, renal, ophthalmic, neurological, cerebrovascular, and peripheral vascular systems. As a result of the disease and its complications, people with diabetes have more frequent and intensive encounters with the healthcare system. ${ }^{1}$ The economic burden of diabetes has been calculated in the developed countries by applying conventional prevalence based cost of illness techniques. ${ }^{2}{ }^{3}$ Various studies have had differing methods of calculating costs, for example, some studies have calculated costs specifically attributable to diabetes and excluded costs associated with complications; whereas other studies have included cost of some complications of diabetes and excluded others. One consistent finding across these studies is that diabetes mellitus poses a significant economic burden. ${ }^{1-9}$ Studies show the relative cost for diabetes to be between $2 \%$ to $3 \%$ of every country's healthcare expenditure. ${ }^{10}$ Gray et al, from England, found a net incremental cost for implementing intensive blood sugar and blood pressure control for all people of type 2 diabetes to be $£ 100.5$ million (as per 1999 prices). ${ }^{11}$

Comprehensive costs of treatment studies from developing countries are scarce. There have been few studies from India ${ }^{12-17}$ that have calculated the cost of care of diabetes mellitus. In recent times, changing economic trends have meant that evaluation of treatment costs is no longer a subject of mere academic interest, even in the developing world. The need for such studies is thus obvious. As most of the patients with diabetes mellitus are treated as outpatients, this study was undertaken in a tertiary care multispecialty hospital to assess the cost of ambulatory care of diabetes mellitus.

\section{METHODS}

This study was part of the larger study that compared the cost of illness of schizophrenia with diabetes mellitus in the setting of a developing country and to assess the influence of certain sociodemographic and clinical variables on the cost of treatment.

\section{Patients}

Fifty patients were chosen from outpatient attendees by purposive sampling at the diabetic clinic of a large multispecialty teaching hospital in north India. Diabetes mellitus was diagnosed according to WHO criteria. ${ }^{18}$ For patients to be included, they had to be between 20 to 50 years of age, to have an illness duration of 5-10 years, and be living with (and accompanied by) relatives. Information was obtained from patients and relatives, and scrutiny of medical records.

\section{Relatives}

Information was also obtained from a relative accompanying the patient. A relative had to be a healthy adult living with the patient and intimately involved in their care. Families with more than one member suffering from a chronic illness were excluded as assessment of several parameters, including cost of treatment, and attribution to a particular patient's illness become quite complicated in such cases.

\section{Assessments}

Demographic, clinical, and treatment details were obtained using pre-designed structured forms. Disability was assessed by using the schedule for assessment of psychiatric disability (SAPD), which is an Indian modification of the WHO disability assessment schedule-II. The SAPD items are grouped into four (or five) main areas of disability including personal, social role, (marital role in the married), occupational, and global disability. Ratings are done on a six point scale. It has been used previously in patients with psychiatric disorders, as well as in those with diabetes mellitus. Adequate reliability and ability to discriminate between different patient groups have been shown. ${ }^{19}$

Abbreviations: SAPD, schedule for assessment of psychiatric disability; $C A Q$, costs assessment questionnaire 
The instrument to measure costs of treatment, the costs assessment questionnaire (CAQ), was specially designed for this study. It was based on a number of questionnaires used earlier to calculate costs of care of different illnesses in developing countries. The questionnaire had provision for measuring direct, indirect, and provider costs. Direct costs were defined as the actual monetary expenditure related to treatment of an illness. ${ }^{20}{ }^{21}$ Direct costs incurred by patients and their families included costs of travel, lodging, food, drugs bought, investigations undertaken and paid for, money spent on administrative work or other treatments, etc. The part of the direct costs of treatment borne by the hospital services, for example, salaries of health professionals, cost of investigations, infrastructure costs, etc, were evaluated under a separate head referred to as provider's cost. Indirect costs referred to the monetary value of lost output attributable to reduced or lost productivity of patient and caregiver caused by illness, disability, or injury, and family costs in looking after a sick relative. ${ }^{22}$ Indirect costs included loss of earnings of patients and family members, increased household expenditure as a direct result of the patient's illness, for example, loans taken to meet costs of treatment.

The study was approved by the institute research and ethics committee.

Patients (and relatives) attending the diabetic clinic of the endocrinology department were approached and those fulfilling selection criteria were identified. Written informed consent was taken from those willing to participate in the study. Information required to calculate costs was obtained from patients, their relatives, treating team members, medical records (including prescriptions, bills, etc), and hospital data. Costs of treatment were assessed twice. The first assessment covered all costs incurred during a three month period before the entry. The second assessment was carried out three months after entry and covered all costs incurred during the period between the two assessments. At the time of the first intake, patients and relatives were educated about the aims of the study and asked to keep all bills, prescription slips, etc, relating to the patient's treatment, so as to improve the accuracy of cost estimates.

\section{Statistical analyses}

The data were analysed using the statistical package for social scientists version 10 (SPSS-10). Descriptive statistics in terms of frequency counts and percentages were used for discrete

Table 1 Clinical and treatment details

\begin{tabular}{ll}
\hline Variables & $\begin{array}{l}\text { Diabetes mellitus } \\
(\mathbf{n}=50)\end{array}$ \\
\hline Duration of illness (y) (mean (SD)) & $7.18(02.09)$ \\
Average FBG (mmol/I) (mean (SD)) & $8.76(3.09)$ \\
Average PPBG (mmol/I) (mean (SD)) & $12.07(4.33)$ \\
SAPD scores (mean (SD)) & $3.59(2.42)$ \\
Overall behaviour & $2.64(2.18)$ \\
Social role & $1.34(1.29)$ \\
Social role (marital) & $1.56(1.27)$ \\
Occupational role & $1.33(0.61)$ \\
Overall disability & $1.05(0.85)$ \\
Number of visits in six months (mean (SD)) & $3.48(1.86)$ \\
Average number of drugs per patient (mean & \\
(SD)) & $07(14 \%)$ \\
Oral hypoglycaemics & $13(26 \%)$ \\
Insulin & $30(60 \%)$ \\
Oral hypoglycaemics and insulin & $26(52 \%)$ \\
Antihypertensives & $25(50 \%)$ \\
Other drugs* &
\end{tabular}

FBG, fasting blood glucose; PPBG, postprandial blood glucose; SAPD, schedule for assessment of psychiatric disability. *Other drugs included vitamin supplements, amitriptyline, and antilipid agents. variables such as sociodemographic variables, clinical variables, and treatment characteristics. Mean and standard deviations were calculated for all the continuous variablesthat is, certain sociodemographic variables, fasting blood sugar and postprandial blood sugar, SAPD, and various costs variables. Cost at first and second assessment were compared using Student's $t$ test. Spearman's correlation coefficients tests were used to determine the association of social and clinical parameters with costs.

\section{RESULTS}

\section{Demographic profile}

As expected the sample was 42.48 years old (range 20 to 50 years) and mostly married $(90 \%)$. The sex ratio showed predominance of women (62\%), however, this was probably an artefact of sample selection. To be included in the study, patients had to be accompanied by attendants. It was found that most of the male patients attending the diabetic clinic usually came unaccompanied, while female patients were more often accompanied by relatives. This could have resulted in a skewed sex distribution in the diabetic group with an excess of female patients. Most of the women were housewives; this could also have had an effect on employment status. The income of the sample was 3516 rupees/ month. Most patients were educated beyond primary school (70\%), belonged to nuclear family $(62 \%)$, and came from urban background (78\%).

\section{Clinical profile (table 1)}

The average duration of diabetes was 7.18 years. The sample consisted mainly (86\%), of patients with type 2 diabetes mellitus, which is consistent with the prevalence rate of two subtypes reported in various studies from India. ${ }^{23}$ As expected, most common presenting symptoms were osmotic features $(62 \%)$, such as polyuria, polyphagia, and polydipsia. The average blood glucose values of patients were far from optimum as defined by American Diabetic Association (average pre-prandial glucose to be $4.44-6.66 \mathrm{mmol} / \mathrm{l}),{ }^{24}$ showing poor glycaemic control. The fact that about two thirds of the sample had microangiopathy, also suggests that

Table 2 Direct and provider costs (rupees) over six months

\begin{tabular}{ll}
\hline & $\begin{array}{l}\text { Mean cost over six months (SD) } \\
\text { (n=50) }\end{array}$ \\
Cost variables & $458.96(756.58)$ \\
\hline Direct costs & $72.66(145.86)$ \\
Travel cost & 00.00 \\
Food on the way to hospital & $0.2(1.41)$ \\
Accommodation & $277.80(320.39)$ \\
Paperwork & $3076.28(2546.92)$ \\
Investigations & $1811.20(1295.95)$ \\
Total drug costł & $648.16(1097.38)$ \\
$\quad$ Antidiabetic drugs & $616.92(1365.94)$ \\
Antihypertensive & $998.44(1709.30)$ \\
$\quad$ Other drugs* & $82.08(268.60)$ \\
Dietary management & $4966.42(4270.42)$ \\
Cost of treatment from other sourcest & \\
Total direct costs & $78.58(51.0)$ \\
Provider's costs & $12.30(33.4)$ \\
Consultation with doctors & $7.6(33.71)$ \\
Liaison consultations & $60.84(42.39)$ \\
Investigations & $46.23(31.56)$ \\
Nursing costs & $205.55(140.82)$ \\
Infrastructure/running costs & \\
Total provider's cost & \\
\hline &
\end{tabular}


glycaemic control had not been adequate over the years Forty four per cent of the patients had associated hypertension, which tallies with usual prevalence of this complication. Only a few patients (4\%) had macroangiopathy. When taken together $78 \%$ of the patients had microangiopathy, macroangiopathy, or hypertension. Scores on the SAPD showed higher disability in the domains of overall behaviour and social role. Most of the patients had received oral hypoglycaemic agents for a long period before the study, mainly glibenclinamide $(50 \%)$, which is usually the first hypoglycaemic agent to be prescribed. Most of the patients during the study period were receiving a combination of oral hypoglycaemic agents and insulin, or two oral hypoglycaemic agents. This was probably a reflection of longer duration of diabetes in most of the sample. Nearly half of the sample was receiving antihypertensives (50\%-52\%) and other drugs $(44 \%-54 \%)$ such as vitamin supplements, amitriptyline, and antilipid agents. The average number of drugs being received by patients was 3.44 (SD 1.86) at first and $3.52(1.86)$ at the second assessment.

\section{Costs of care}

All costs were assessed using the CAQ. Assessments were carried out twice. The second assessment was then carried out three months after the first one. Comparisons of costs between the three month intervals showed that total direct and provider's costs were significantly higher for the first intake period. There were no differences in the indirect costs. The differences in direct costs and provider's costs could almost entirely be accounted for by the number of visits, which were significantly higher during the first assessment period. Therefore average costs were calculated for the entire six month period.

\section{Direct costs (table 2)}

Total direct treatment cost of diabetes mellitus over the entire six month period amounted to 4966.42 rupees (SD 4270.42). The money spent on drugs was the highest -3076.28 rupees (SD 546.92). Another important contributor to the direct cost was expense attributable to dietary modifications, this was followed by travel costs and cost of investigations. Money spent on food while attending the hospital and treatment from other sources was almost similar. Paperwork costs were minimal, and there was no accommodation cost as most of them came from nearby localities and the visit was equivalent to visit for day care.

Table 3 Indirect costs (rupees) over six months

\begin{tabular}{|c|c|}
\hline Determinants of costs & $\begin{array}{l}\text { Over six months } \\
\text { (SD) }\end{array}$ \\
\hline Number of days lost by patient because of illness & $5.58(24.23)$ \\
\hline $\begin{array}{l}\text { Number of days lost by patient for attending the } \\
\text { hospital }\end{array}$ & $0.92(1.67)$ \\
\hline $\begin{array}{l}\text { Number of days lost by caregiver because of } \\
\text { patient's illness }\end{array}$ & $0.94(3.22)$ \\
\hline $\begin{array}{l}\text { Number of days lost by caregivers for attending } \\
\text { the hospital because of patient's illness }\end{array}$ & $1.61(1.98)$ \\
\hline Income/day of patients & $117.22(190.35)$ \\
\hline Income/day of care givers & $152.98(211.59)$ \\
\hline \multicolumn{2}{|l|}{ Average indirect costs over six months } \\
\hline Cost variable & $\begin{array}{l}\text { Mean cost over six } \\
\text { months (SD) }\end{array}$ \\
\hline Total loss of income of the patient & $1263.28(4116.46)$ \\
\hline Total loss of income of caregiver & $0823.46(2492.74)$ \\
\hline Other expenditures* & 0000.00 \\
\hline Total & $2086.74(5050.03)$ \\
\hline
\end{tabular}

\section{Provider's costs (table 2)}

Total provider's cost for diabetes mellitus over six months period was 205.55 rupees (SD 140.82). Cost of consultations with doctors, nursing cost, and infrastructure and running costs constituted the largest proportion of the provider's costs.

\section{Indirect costs (table 3 )}

Total mean indirect treatment costs over the six months were 2086.74 rupees (SD 5050.03). Loss of income of the patient comprised a large portion of indirect costs. This was followed by loss of income of caregivers.

\section{Total treatment costs}

The total treatment cost was 7254.07 rupees, for the six month period. Direct treatment costs made up for slightly more than two thirds $(68.4 \%)$ of the total treatment costs. The proportion of indirect costs was much less $(28.76 \%)$, and that of provider's costs was minimal $(2.8 \%)$.

\section{Correlates of cost of care}

\section{Sociodemographic parameters}

None of the sociodemographic parameters apart from education had any significant correlation with total costs, direct costs, indirect and provider's costs. Total indirect costs were lower for patients with education less than five years (398.66 (485.39) rupees) than those educated beyond five years $(2810.20$ (5904.32) rupees). This difference was also significant (Mann-Whitney U value 153, p<0.05) and was most probably attributable to higher income in more educated patients.

\section{Clinical parameters}

The number of visits over the six month period correlated with total costs as well as the indirect and provider's costs $(\mathrm{p}<0.01)$. Furthermore, the number of drugs received per patient showed positive correlations with the direct and total treatment costs over six months $(\mathrm{p}<0.01)$.

\section{DISCUSSION}

Examined from a general perspective, cost of diabetes studies can be categorised by three study designs. These include designs based on diagnostic category data (ICD codes) from general population surveys, responses from persons with diabetes, and cost projections from previous studies. Cost estimates in this study were loosely based on the prevalence based and "bottom up" approaches, which are particularly helpful in evaluating and comparing economic burden of different disorders. ${ }^{22} 25$ Indirect costs were calculated using the "human capital" principle, ${ }^{20}$ although future mortality costs could not be assessed because of difficulties in obtaining requisite information. Although cost estimations were primarily based on a survey of patients, to increase reliability and comprehensiveness of data, information was also obtained from other sources such as relatives, treating teams, medical records, and hospital sources. Costs were assessed twice and added up to yield average figures over a six month period to meet previous recommendations for a minimally acceptable duration of three to six months for calculating treatment costs. ${ }^{21}$ Finally, costs were assessed as comprehensively as possible and every effort was made to ensure that important components of costs were estimated with some degree of accuracy. The study was limited by small sample size, comparatively short period of evaluation, and use of an instrument to measure costs, which had not been properly validated. Other aspects of burden, for example, social burden, intangible costs (stress/stigma borne by those affected) could not be evaluated. In contrast with earlier studies (for example, Suleiman et $a^{26}$ ) this study had a mix of 
patients with type 1 and type 2 diabetes mellitus because this was more representative of patients attending the diabetic clinic.

In a review Songer et $a^{27}$ noted that the advantage of surveying people is that more precise estimates of the costs of diabetes can be attained because individual costs and utilisation patterns are observed directly, rather than estimated from ICD categories. Also, if a representative sample of the population is used, data based on the reports of people with diabetes are much more likely to reflect the experience of the diabetes population than are data based on diagnostic categories. The disadvantage of surveying costs among a representative sample of people with diabetes is that it is an expensive process. Furthermore, many of the national estimates related to diabetes are based on the responses of a limited number of persons.

\section{Costs of care of diabetes mellitus \\ Total costs}

The total cost of care of diabetes was estimated at 14517.42 rupees ( 263.78 euros) per person annually in this study. Total cost estimates as reported by previous studies range from $\$ 2.6$ billion in $1969^{28}$ to $\$ 98.2$ billion in $1997 .^{7}$ Although several of the reports consider only direct costs, most include both direct and indirect costs. ${ }^{35-7}$ The total cost in this study cannot be compared with previous studies done in developed countries because of the methodological differences and vast differences in economic/social set ups between developing and developed countries. On the other hand, studies from developing countries are limited and varied widely in the methodology used to estimate costs. ${ }^{12-16}$

\section{Direct costs}

The direct cost of care of diabetes was estimated to be $71.25 \%$ of the total cost and was much more than indirect costs $(28.75 \%)$. The proportion of costs borne by the hospital $(2.83 \%)$ was comparatively less. The greatest bulk of the costs $(42.38 \%)$ were made up of money spent by patients on buying drugs.

The estimate of cost of diabetes from the developed countries show the direct costs of diabetes ranging from $\$ 1.0$ billion in $1969^{328}$ to $\$ 11.6$ billion in $1986,{ }^{9}$ and making up about $38 \%$ of the total costs in 1969 and then varying from $30 \%$ to $75 \%$ of the total costs. Besides the methodological differences, the consistent finding in most of the studies is that the costs for hospital care clearly make up most of the direct costs related to diabetes. When we see our results, cost of drugs and provider's cost formed the largest amount, which is similar to the findings from developed countries, but most of the money spent on drugs was by the patient and his family, which is unlike that of developed countries but similar to findings from previous studies from India. ${ }^{15}$

Studies from India have similarly estimated the cost of outpatient treatment of diabetes mellitus. A study by Rayappa et $a l^{12}$ estimated that the annual direct cost of routine care in 1998 was about US\$191 (about 8595 rupees) and the mean direct cost for hospitalisation for a diabetes related episode was about US\$208. In another study, the same author ${ }^{13}$ showed that duration of illness and number of complications is the most important determinant of direct costs and hospitalisation costs. On the other hand the annual direct cost of ambulatory care estimated by Kapur et $a l^{14}$ in year 2000 was 4724 rupees; by Shobhana et al ${ }^{15} 8578$ rupees for type 1 diabetes mellitus and 3310 rupees for type 2 diabetes mellitus in the year 2000. Compared with this study, direct costs were much lower in previous studies. Several disparities in the patient samples and methodology might have contributed to these differences for example the numbers of complications among patients with diabetes were much more in this study, perhaps showing that patients were more seriously ill. Furthermore, it was not clear whether the studies by Rayappa et al ${ }^{12}{ }^{13}$ included the dietary costs, which formed a substantial proportion (13.76\%) in our study. Studies by Shobhana et a ${ }^{15}$ did not include dietary costs. This could partly explain the higher direct costs obtained in this study. Finally, Rayappa et al ${ }^{12}$ calculated monthly costs, which they extrapolated to obtain total annual costs. As monthly expenditures can differ considerably, any small difference tends to get magnified 12-fold by this method. In another multicentre study from India, Bjork $e t a{ }^{17}$ reported that mean direct cost was 7189 rupees per annum in year 1999, of which cost of drug treatment and disease monitoring tests and check ups was 4724 rupees and hospitalisation cost was 2435 rupees. On comparing the results of our study with the above study, our results are more or less similar if only the components of direct costs are compared, taking into consideration the inflation rates. However, drug costs in our study were considerably less than those reported by Suleiman et al $^{26}$ from Nigeria. These authors found that $92.8 \%$ of the total costs were accounted for by cost of insulin injections, which were imported.

\section{Indirect costs}

Lost earnings of patients and caregivers made up 28.74\% of the total costs. Compared with studies by Rayappa et $a l^{12}$ indirect costs in our study were almost five to eight times higher. The differences in indirect costs could be partly accounted by the different method of estimation, replacement costs, or the friction-cost approach used to measure indirect cost, used in the previous studies. Shobhana et al did not assess the indirect costs.

\section{Provider's cost}

The hospital bore only a very small proportion of the total costs. The fact that the sample consisted entirely of outpatients could have considerably reduced the provider's share of costs. More than $95 \%$ of the total costs of treatment were met by patients and their families of this study, which is similar to the previous studies. ${ }^{15}$

More pertinently, low provider's costs found in this study were in line with the findings of a recent World Health Report, ${ }^{29}$ which stated that in developing low income economies (including India) the government's share of health expenditure was steadily declining. This together with inadequate healthcare facilities in developing countries means that families have to bear the brunt of financial burden, with very little help from elsewhere.

\section{Correlates of cost of care}

In this study there were very few significant associations of cost of care with demographic factors. Total indirect costs were significantly lower for patients with lower education. This difference was similar to that reported by previous studies from India and was most probably attributable to higher income in more educated patients. ${ }^{15}$ The number of visits to the hospital correlated with all types of costs lending further credence to the suggestion that cutting down on the number of visits could be one of the most effective ways of cost reduction. All types of costs except indirect cost also correlated with number of drugs prescribed. Few correlations were seen between the scores on various subscales of the SAPD and costs over six months. Only indirect costs and provider's costs showed significant positive correlations with scores on the social role (marital) subscale.

\section{Conclusions/implications}

The principal findings of this study have several possible implications for the treatment of diabetes in developing 
countries like India. Firstly, this study showed that it is an expensive illness to treat even in developing countries, although the pattern of costs was quite different from that of developed ones. There is a need to increase awareness of these facts among all health professionals involved in the care of diabetes in developing countries, as well as health policy makers of these countries. This work also makes it clearly evident that the largest share of costs was being borne by patients and their families. Any efforts at cost reduction should, therefore, have the family as its focus, and relieving the family of this financial burden needs to be prioritised.

\section{Authors' affiliations}

S Grover, A Avasthi, S Chakrabarti, P Kulhara, Department of Psychiatry, Postgraduate Institute of Medical Education and Research, Chandigarh, India

A Bhansali, Department of Endocrinology, Postgraduate Institute of Medical Education and Research

Funding: none.

Conflicts of interest: none declared.

\section{REFERENCES}

1 Rubin RJ, Altman WM, Mendelson DN. Health care expenditures for people with diabetes mellitus, 1992. J Clin Endocrinol Metabol 1994;78:809A-809F.

2 Rice DP, Hodgson TA, Kipstein AN. The economic costs of illness: a replication and update. Health Care Finan Rev 1985;7:61-80.

3 Entmacher PS, Sinnock P, Bostic E, et al. Economic impact of diabetes. In: National Diabetes Data Group, ed. Diabetes in America: diabetes data compiled, 1984. Bethseda: National Institute of Health, 1985:85-1468.

4 Jacobs M, Sena N. The cost of hospital for the late complications of diabetes in the United States. Diabet Med 1991;8:523-9.

5 Javitt JC, Chiang YP. Economic impact of diabetes. In: National Diabetes Data Group, ed. Diabetes in America. 2nd ed. Bethseda, MD: National Institute of Health, 1999:601-611.

6 American Diabetes Association. Direct and indirect costs of diabetes in the United States in 1992. Alexandria, VA: American Diabetes Association, 1993.

7 American Diabetes Association. Economic consequences of diabetes mellitus in the US in 1997. Diabetes Care, 1999;21:296-320.

8 Harris MI. Diabetes in America: epidemiology and scope of the problem. Diabetes Care 1998;21(suppl 3):C1 1-14.
9 Huse DM, Oster G, Killen AR, et al. The economic costs of non-insulin dependent diabetes mellitus. JAMA 1989;262:2708-13.

10 Jonsson B. The economic impact of diabetes. Diabetes Care 1998;21(suppl 3):C7-10.

11 Gray A, Clarke P, Farmer A, et al. Implementing intensive control of blood glucose concentration and blood pressure in type 2 diabetes in England: cost analysis (UKPDS 63). BMJ 2002;325:860-5.

12 Rayappa PH, Raju KNM, Kapur A, et al. Economic cost of diabetes care: the Bangalore urban district diabetes study. Int J Diab Dev Countries 1999;19:83.

13 Rayappa PH, Raju KNM, Kapur A, et al. The impact of socio economic factors on diabetes care. Int J Diab Dev Countries 1999;19:7-16.

14 Kapur A. Cost of diabetes in India. The CODI study paper presented at the Novo Nordisk. In: Kapur A, Joshi JK, eds. Diabetes Update Proceedings. Bangalore: Communication Workshop (P), 2000:71-7.

15 Shobhana R, Rama PR, Lavanya A, et al. Expenditure on health care incurred by diabetic subjects in a developing country-a study from southern India. Diabet Res Clin Pract 2000;48:37-42.

16 Shobhana R, Rama PR, Lavanya A, et al. Costs incurred by families having type 1 diabetes in a developing country-a study from southern India. Diabet Res Clin Pract 2002;55:45-8.

17 Bjork S, Kapur A, King H, et al. Global policy: aspects of diabetes in India. Health Policy 2003;66:61-72.

18 The Expert Committee on the Diagnosis and Classification of Diabetes Mellitus. Report of expert committee on the diagnosis and classification of diabetes mellitus. Diabetes Care 1997;20:1183-99.

19 Thara R, Rajkumar S, Valecha. The schedule for assessment of psychiatric disability-a modification of the DAS-II. Indian J Psychiatry 1988;30:47-53.

20 Rice DP, Kelman S, Miller LS. The economic burden of mental illness. Hosp Community Psychiatry 1992:43:1227-32.

21 McCrone P, Weich S. Mental health care costs: paucity of measurements. In: Thornicroft G, Tansella M, eds. Mental health outcome. London: Springer, 1996:131-42.

22 Shah A, Jenkins R. Mental health economic studies from developing countries reviewed in the context of those from developed countries. Acta Psychiatr Scand 2000;101:87-103

23 Ramachandran A. Epidemiology of type 2 diabetes mellitus in India. In: Dash RJ, ed. New vistas in type 2 diabetes. Chandigarh: Relume printec, 2000: 1-8.

24 American Diabetes Association. Clinical practice guidelines 2000. Diabetes Care 2000;23(suppl 1):S1-116.

25 Rice DP, Miller LS. Health economics and cost implications of anxiety and other mental disorders in the United States. Br J Psychiatry 1998:34:4-9.

26 Suleiman TG, Ohaeri JU, lawal RA, et al. Financial cost of treating outpatients with schizophrenia in Nigeria. Br J Psychiatry, 1997; 171:364-8.

27 Songer TJ. The economics of diabetes care:USA. In: Alberti KGMM, Zimmet P, DeFronzo RA, eds. International textbook of diabetes mellitus. 2nd ed. Chichester: Wiley, 1997.

28 Entmacher PS. Report of economic impact of diabetes, Vol 3. Part 2. Washington, DC: US Government Printing Office, 1976.

29 World Health Organisation. World health report. Geneva: WHO, 2000

\section{bmjupdates+}

bmjupdates+ is a unique and free alerting service, designed to keep you up to date with the medical literature that is truly important to your practice.

bmjupdates+ will alert you to important new research and will provide you with the best new evidence concerning important advances in health care, tailored to your medical interests and time demands.

\section{Where does the information come from?}

bmjupdates+ applies an expert critical appraisal filter to over 100 top medical journals A panel of over 2000 physicians find the few 'must read' studies for each area of clinical interest

Sign up to receive your tailored email alerts, searching access and more...

www.bmjupdates.com 